\title{
Development and research on integrated protection system based on redundant information analysis
}

\author{
Jinghan He, Lin Liu*, Wenli Li and Ming Zhang
}

\begin{abstract}
Facing the growth of energy demand and the worldwide interests in renewable energy sources, smart grid has been proposed in order to accommodate the needs of power grid development. In China, digital substations have been widely applied. Moreover, as the worldwide interest and development in smart grid have increased significantly, the digital information availability and communication capability of modern substation have been improved. Different with traditional substation protection configuration based on local information, Integrated Protection (IP) is used to denote the integration of several protective devices for multiple power equipment within the substation into one protective relay, obtaining all the real time information of the substation by communication network. The analysis of sharing information and cooperation among different protection functions helps to realize more reliable and sensitive fault detection. This paper describes several different integrated protection schemes and their respective advantages and disadvantages. The principles and functions applied in integrated protection systems are addressed to provide an overview of the current state of the technology. A new coordinated protection system based on inter-substation information is proposed and simulation study is discussed to verify the improved reliability and sensitivity.
\end{abstract}

Keywords: Integrated protection, Substation, Smart grid, Redundant information, IEC61850

\section{Introduction}

POWER systems are facing challenges due to the deregulation of the electricity market, environmental concerns and the impact of changing from a fossil fuel dominated system to one based on low carbon sources. The issues are further complicated by recent major blackouts, customers' expectation of high system reliability and the impact of power electronics equipment. Power systems need to be developed in the direction of high reliability, flexibility, intelligence and sustainability. All these challenges lead to high requirement on power system protection.

Traditional power systems usually have main and backup protections for every local plant. Main protection abides by the well-established and well-proven "dispersed and independent" principle. Backup protection issues tripping signals when the main protection or its associate

\footnotetext{
* Correspondence: 11117363@bjtu.edu.cn

School of Electrical Engineering, Beijing Jiaotong University, Beijing 100044, China
}

circuit breaker fails to operate. These signals then trip the circuit breakers to isolate un-cleared faults from the network. They traditionally coordinate with the main protection using time delays and appropriate choice of settings [1]. The rapid development of power systems further complicates the setting and coordination of backup protection, and the resulting extended trip times risk operating safety and system stability.

The application of various intelligent secondary equipment and the construction of a reliable communication network are the fundamental factors for promoting the development of new protection systems. With the widely spread application of intelligent electronic devices (IEDs), information digitization and substation communications, the adoption of protection that uses comprehensive information sourced from the local region is required. Extensive studies have been carried out to improve protection performance, which generally involve enhanced utilization of digital and communications technologies. 
The classification of these types of protection can be based on the information domain scope. Wide area protection is based on a wide area measurement system (WAMS) that implements a regional protection and control system [2-7]. This was developed from special integrity protection systems (SIPS) [8] and broadened the role of traditional relay protection from a point to a surface, so that the high standards of dependability and security inherent in modern protection systems can be maintained [9]. Wide area protection responds to various system disturbances through the analysis of wide area information and the evaluation of the system states. This type of protection involves the use of system-wide or regional information and the communication of selected local data to a remote location. It is designed to counteract the propagation of a large disturbance, and delivers better sensitivity and effectiveness as compared with traditional SIPS [10]. At present, because of communication delays and high requirement to Ethernet bandwidth, there are still many application issues of wide area protection for a large scale grid.

Protection schemes whose information domain is within a substation or within a local regional area network have also been proposed. The concept of integrated protection (IP) $[11,12]$ was proposed on the background of digital substation and smart grid. Integrated network protection (INP) is based on IP, and its information range is extended to several adjacent substations. All these studies have encouraged the protection and control system to utilize comprehensive information to achieve better performance and to satisfy the functional requirements of a modern grid.

Previous work summarized above indicates protection based on comprehensive information can adapt to the evolution of the power network and optimize its performance. China, U.S., Canada, Korea, and European Community (EC) countries have started research and development on integrated protection technologies and applications. For example, researchers in China applied integrated substation-area protection devices in 6 new generation intelligent substations in 2012 and the number has increased to 48 in 2014. The state grid corporation of China has announced that $65 \%$ of the $110 \mathrm{kV}$ substations will adopt integrated protection devices by 2020 .

The rest of the paper is organized as follows. Section II describes several different kinds of integrated protection schemes and their respective advantages and disadvantages. Section III illustrates the protection principles and functions applied in integrated protection systems. A new coordinated protection system based on intersubstation information is proposed in Section IV, and finally, this paper is concluded in Section V.

\section{Integrated protection schemes}

Based on the optical transducer, data sampling with merging units and optic-fiber communication, the data collection part of protection device is separated. Different from conventional protection device, applying the intelligent breaker makes it possible that the protection device only keeps the data processing and communication part. With the rapid development and maturity of computer and electronic technology, high reliable integration and modularization of the protection device have become a development trend. Taking advantages of the compatibility with Common Information Model (CIM) of IEC 61850, communication between devices in substation automation systems becomes flexible. This technology has been applied in the protection scheme in intelligent substations and implemented in some latest power system protection products.

In the following, some of the different integrated protection schemes based on different communication infrastructures are presented, and their respective advantages and disadvantages are briefly explained.

\section{Integrated substation protection scheme for rural substations}

Rural substations are the vital nodes of rural smart grid and are commonly $35 \mathrm{kV}$ substations in China, especially in the central and western regions. At the end of 2012, there are $1650035 \mathrm{kV}$ substations in State Grid and 1228 of them are new intelligent substations. On the background of smart grid and intelligent devices, research of integrated protection scheme for rural substations is driven by the development requirement.

A typical architecture of the integrated protection scheme of $35 \mathrm{kV}$ substations consisting of three levels, is shown in Fig. 1. There is no process bus in the network and all the protection devices are connected to the merging units (MUs) and the intelligent units (IUs) in peer-to-peer mode. The station bus is in single-network structure considering the cost. Two integrated protection and control devices are in the bay level to receive the sample value information from the process level, and to conduct elaborate calculations and send decision signals to circuit breakers.

For new intelligent substations, two integrated protection central processing units (IPCPUs) are in the bay level and each one can protect all the primary devices in the substation. The adoption of dual IPCPUs is to improve the reliability, as one can work as the backup if the other fails. Because the substation area information is integrated in the IPCPU, it is easily to implement many protection functions, e.g. ground fault line detection, under frequency load shedding, voltage and reactive power automation control. GPS is used as the time server and the IRIG-B signals are used to synchronize all the data. 


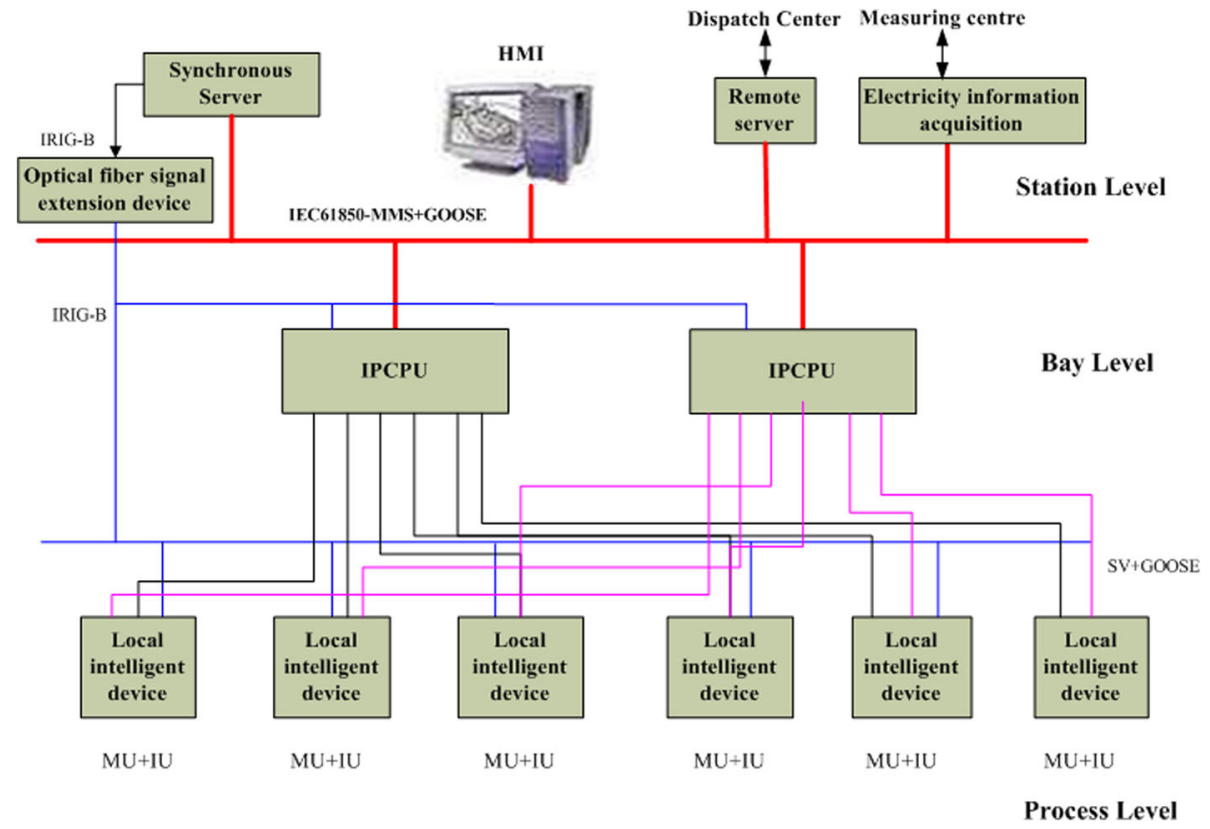

Fig. 1 Structure of integrated substation protection scheme for rural substations. IPCPU means the integrated protection central processing units

For refurbished substations, some protection functions can be set with MUs and IUs in the process level, and all these intelligent devices work together to implement distributed protection with no communication requirement. On the other hand, the IPCPU in bay level works as substation area protection including control and substation automation.

Some latest substation protection products based on this protection scheme have been applied in China, and some operation cases can be found in Table 1 .

\section{1) Advantages}

The integrated substation protection is a costeffective solution for rural substations, with simplified structure and reduced number of required equipment. The substation area information is integrated into the protection unit, and is easy to analyze comprehensive and redundant information to reach higher protection reliability and implement fault analysis. The peer-to-peer communication of the process bus is reliable and secure with low-latencies and sufficient bandwidth [13].

Table 1 Operation cases of latest substation protection products

\begin{tabular}{llll}
\hline No. & Substation Name & Voltage Level & Year \\
\hline 1 & ShiMaChuan (New) & $35 \mathrm{kV}$ & 2009 \\
2 & Weijin (Rebuit) & $66 \mathrm{kV}$ & 2010 \\
3 & HaoTian (New) & $35 \mathrm{kV}$ & 2011 \\
4 & DongTing (New) & $35 \mathrm{kV}$ & 2011 \\
\hline
\end{tabular}

The adoption of dual IPCPUs improves the system reliability.

2) Disadvantages

The optical-fiber interface has large numbers and the connection is complex, and thus this scheme is only suitable for small-scale substations. Furthermore, the scalability of this protection scheme is limited which does not meet the requirement of device networking.

\section{Integrated substation protection scheme for high voltage substation}

Different with rural substations, high voltage substations have much more bays and power equipment. Considering large numbers of information interface, different voltage-level sides have their own information sharing networks. Figure 2 shows the architecture of the integrated protection scheme of $110 \mathrm{kV}$ substation. In the process level, the voltage and current signals acquired by the voltage transformers (VTs) and current transformers (CTs) are digitalized by the MUs and sent through the process bus to the bay level to achieve data sharing. The term "Integrated Substation Protection" (ISP) in the bay level, is used to denote the integration of several protective devices for multiple power equipment within the substation into one protective relay [1]. GPS signals are used to keep the synchronization of all the sample data. After the data processing and analysis of the sampling data from different devices in the substation, ISP send GOOSE messages including trip signals to the IU to realize the operation of the circuit breakers. Station level includes the Human Machine Interface (HMI) 


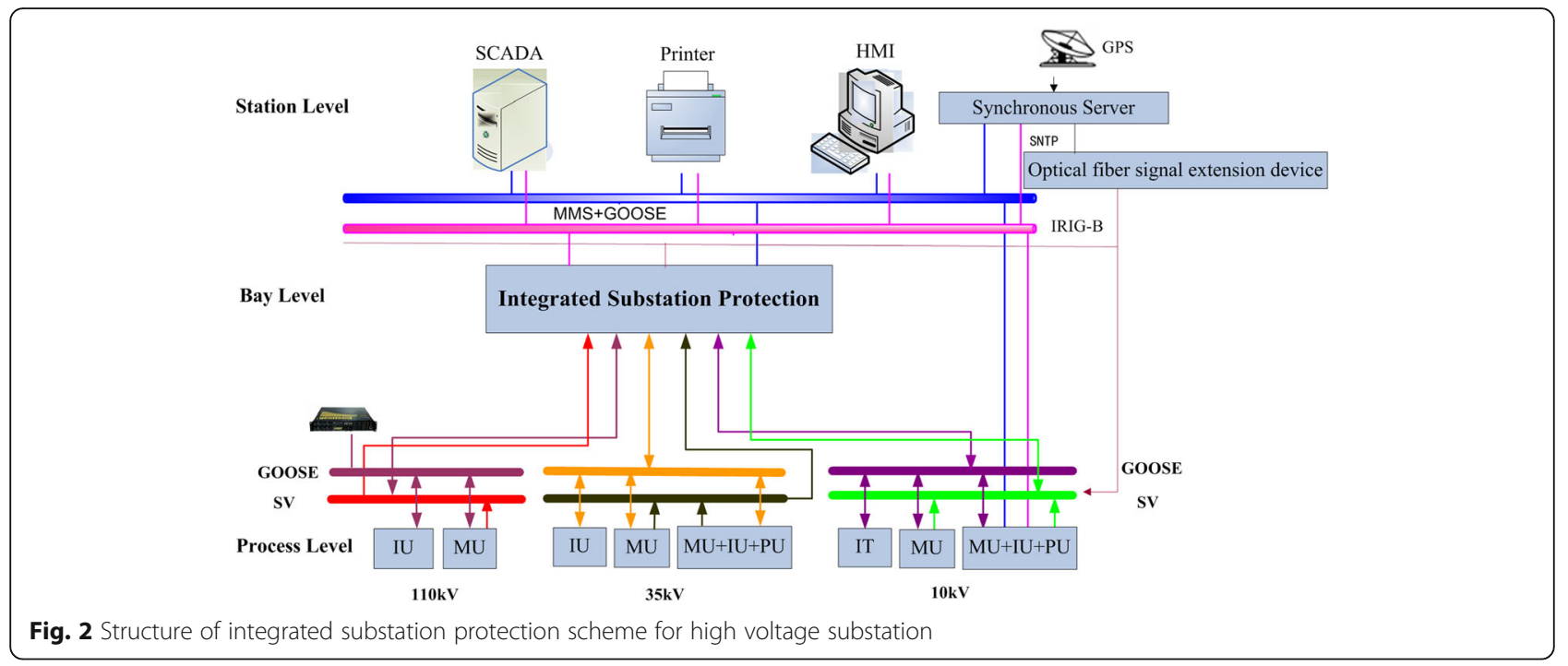

and SCADA system. Through the station bus, the status data of various components are available to operators for monitoring and operation purposes. The manual control signals flowing in the opposite direction can also be issued through the network to perform some control functions by the protection units (PUs). Considering the communication reliability, both the process bus and station bus are in dualnetwork structure.

One protection product based on this protection scheme has been applied in LongChang $110 \mathrm{kV}$ traction substation in 2011.

\section{1) Advantages}

This protection scheme has good scalability and the information sharing network structure can meet the requirement of smart grid development. This communication network can also save optical-fiber interfaces and reduce infrastructure costs in project implementations. On the other hand, the integrated substation protection is based on substation-domain information and has better reliability.

2) Disadvantages

The data sampling relies on external clock (GPS) but the transmission time delay of switch network is not a fixed value, and thus, the SV synchronization has a high risk. For GOOSE network, its transmission time delay is not fixed and the tripping time of the circuit breakers may be effected. Nowadays, the cost of fiber interface switch is high and thus, some idle interfaces should be considered as backup in project construction. The application cost should be given more attention.

\section{Hierarchical regional area protection}

The hierarchical regional area protection is a protection system involving the information of the whole power grid to achieve reliable and adaptive fault detection and clearance. It is a combination of protection information, functions and coordinated strategy. There are three protection subsystems: local protection subsystem, substation area protection subsystem and wide area protection subsystem (as shown in Fig. 3).

Local protection subsystem (LPS): protection devices are installed for every local item of plant. Main protection abides by the well-established and well-proven "dispersed and independent" principle, and reliable and fast fault clearance is achieved based on local data analysis.

Substation area protection subsystem (SAPS): this kind of protection is different to the ISP, because its integrated information is the status data of the local protection devices and circuit breakers. SAPS can also communicate with adjacent substations through the synchronous digital hierarchy (SDH) [14], to receive status of the opposite terminal circuit breaker. Through centralized analysis, useful decisions can be given based on redundant information, in order to improve the system operation reliability. The SAPS also works as the sub-substation's wide area protection subsystem.

Wide area protection subsystem (WAPS): in this subsystem, protection and control decisions are based on wide area PMU information, and it responds to various system disturbances through the analysis and evaluation of the system states.

Coordinated strategies: the WAPS collects the status information of the SAPS and control signals are issued though the SAPS to relevant equipment. The SAPS collects the data of LPS and can send control signals immediately without cooperating with the LPS.

1) Advantages

Taking advantages of broadening information domain, extensive information and coordinated 


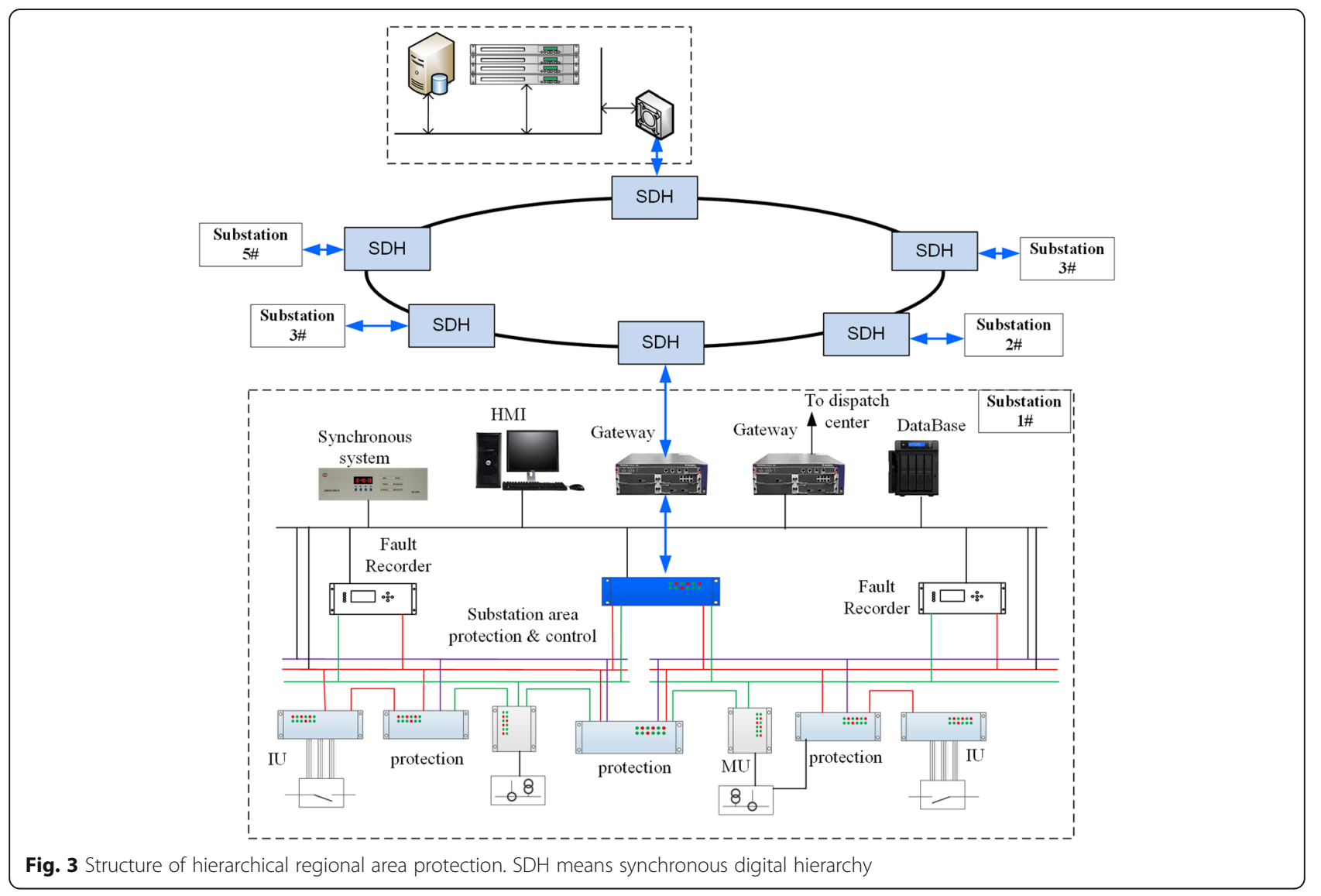

strategies, the pressure of the traditional local protection an be relieved. In addition, based on the regional information, exact faulted section can be located and the protection sensitivity and reliability is significantly improved.

2) Disadvantages

The SAPS and WAPS are both dependent on the communication network. The protection system is likely to lose their functions when the communication network fails. The integrated information of SAPS is the status data, thus it is easy to implement data interaction. However, problems like data missing and high error rate challenge the communication reliability, and the fault tolerance needs to be considered further. On the other hand, the interaction of analog data must pay attention to the synchronization and time delay of the switch. For the WAPS, the PMU configuration is another problem, and a good solution is to keep the balance of enough data and economic cost.

\section{Protection scheme based on multi-agent systems}

Multi-agent technology is a powerful new technique for use in distributed protection systems due to its autonomous, cooperative, and proactive nature. There are already lots of researches on the application of multiagent to protection systems $[15,16]$. For different types of integrated protection schemes presented above, protection functions can be designed in a modularizing mode and implemented based on the multi-agent technology. A protection scheme based on multi-agent systems is analyzed below, as an example.

In the protection scheme, integrated protection functions are divided into different agents according to different missions. Three levels are defined for agent system (as shown in Fig. 4): execution level, coordination level, and organizing level. In the execution level, there are measuring agent ( $\mathrm{M}$ Agent), state diagnose agent (SD Agent) and tripping agent (T Agent). Coordination level includes the basic protection functions and others based on information interaction: searching agent, fault detection agent, fault line selection agent. The top level is the organizing level which works as the agent controller (named as recombination agent).

The agents in the coordination level can not only work independently, but also coordinate with other agents to realize data sharing, backup function and adaptive setting, especially when the network has disturbances.

The agents in the execution level operate based on the communication network, whereas its interaction 


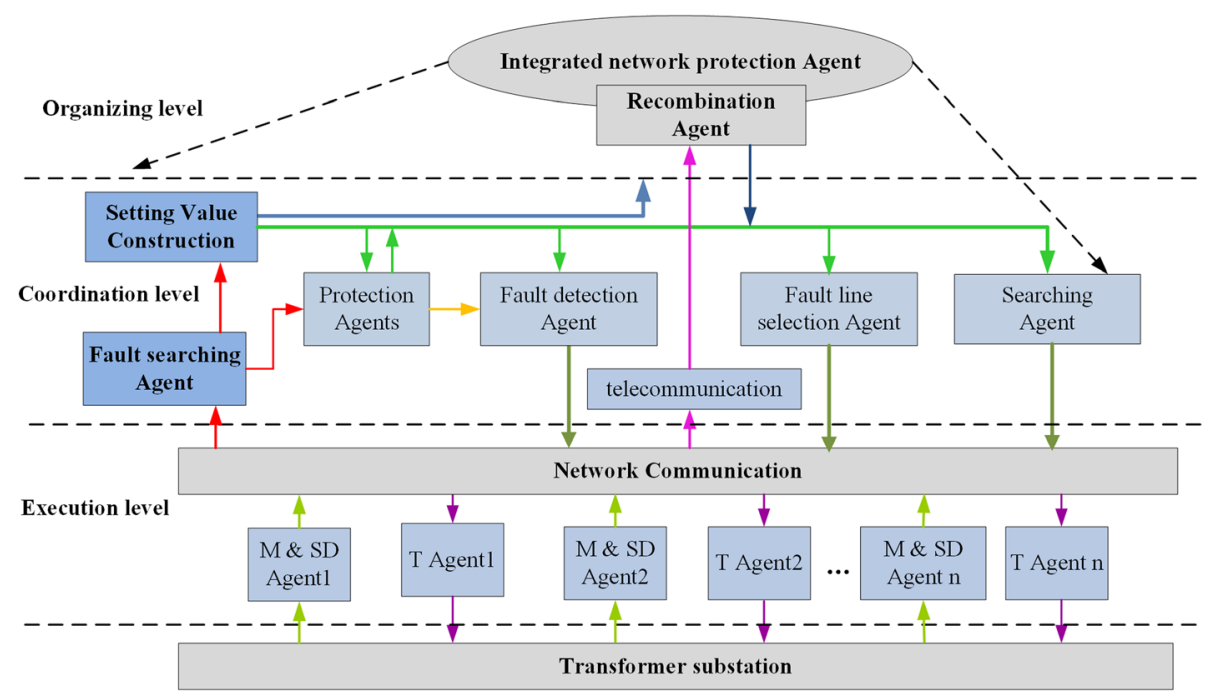

Fig. 4 Structure of multi-agent protection scheme. M Agent means measuring agent. SD Agent means state diagnose agent and T Agent means tripping agent

with the coordination level is solved by software logics. The top level controls all the agents of lower levels by recombination agents.

\section{1) Advantages}

The application of multi-agent technology improves the use of redundant information, and the protection functions and configurations become adaptive to the change of power system resulting in higher protection adaptability and robustness.

2) Disadvantages

The design of the agent structure is complex, including hardware and software. When the scale of the power system is large or the interaction of adjacent substations is considered, optimal agent model needs to be further studied.

\section{Principles and functions}

In the integrated protection schemes, traditional protective principles can work in the centralized relay to protect all the apparatuses within the substation. Based on the further analysis of redundant information, some novel principles are proposed and some solved issues and automation functions are presented below.

\section{Traditional protective principles}

The integrated protection scheme is mainly based on the well-established overcurrent (OC) protection technique. Reference [17] presents a new integrated protection scheme based on the overcurrent protection principle. Reference [11] presents an approach to improve the overcurrent protection by combining the adaptive current and voltage instantaneous protections.
With the rapid development of optical fiber communication technology, current differential protection, owing to its simplicity of principle, higher sensitivity and inherent ability of phase selection, has been extensively used [18]. Current differential relaying works on the detection of the unbalance in current flow into and out of a definite protected zone and it is especially attractive to subtransmission systems since the dynamic changes of power system impedance and power direction are solved in a simple and elegant manner. References [19] and [20] proposed a multi-zone fault clearing protection with a current differential scheme of a fixed protection zone, providing integrated primary and backup protection functions. In the integrated protection scheme [21], an integrated current differential relay, interfaced to the CTs on all of the output lines connected to the substation bus and neighboring substations at the remote ends of the lines, is responsible for the protection of all the transmission lines associated with the substation.

CT saturation caused by external faults may result in a differential current increase or a restraint current decrease leading to protection maloperation. The directional information principle is a good solution to solve this problem. A protection method based on polarity comparison is introduced in [22]. In [23], a directional comparison bus protection is presented.

An integrated protection scheme based on distance protection technique [24] is installed within a substation, and the centralized distance relay is implemented with multiple distance settings to cover all the protected sections. By utilizing the ratio between the sum of the two terminal voltages of the line and that of the two terminal currents, which is defined as integrated 
impedance, a novel transmission line pilot protection principle is presented in [25]. The research in [26] extends the work of Rockefeller [27] and proposes an integrated, hierarchical protection system based on distance relays where settings are adapted to ensure optimized performance under widely varying power system operating conditions.

\section{Novel protection principles}

A new protection scheme for high-speed protection of transmission lines, namely, Integrated Positional Protection scheme, is proposed in [28]. The relay which is based on the fault generated high frequency transient current signals incorporates two novel protection principles of positional protection techniques with and without the synchronization of Global Positioning System (GPS) respectively. The integrated protection technique based on transient current polarity comparison is presented in [29]. The polarity of the transient current component which comes from the faulted direction on the transmission line is different from the one which comes from the other emanating lines. Protection using this principle can protect not only all lines associated with a bus, but also the emanating parallel lines. As shown in Fig. 5, when the fault occurs at $F_{1}$, the polarity of the transient current component $I_{\mathrm{NM}}$ is opposite to that of the $I_{\mathrm{NLL} 1}$ and $I_{\mathrm{NLL} 2}$, while the polarities of $I_{\mathrm{NLL} 1}$ and $I_{\mathrm{NLL} 2}$ are the same. When the fault occurs at $F_{2}$, the polarity of the transient current component $I_{\mathrm{NLL} 1}$ is opposite to that of the $I_{\mathrm{NM}}$ and $I_{\mathrm{NLL} 2}$, while the polarities of $I_{\mathrm{NM}}$ and $I_{\mathrm{NLL} 2}$ are the same. The polarity calculation is based on modulus maximum principle of wavelet transform.

A scheme of Substation-area Differential Backup Protection oriented to intelligent substations is proposed in [30]. Through defining four types of differential zones, fault section can be detected precisely by ordinal searching. The bus protection comprehensive algorithm [31] of information integration and information decentralization is presented based on the integrated protection. Peakscutting-criterion and interpolation fitting compensation methods are also proposed, considering the influence of electronic transformer on bus differential protection.
Moreover, a bus protection method based on current direction comparison is proposed for the integrated protection. For a typical bus structure shown in Fig. 6 (a), the current directions of $\dot{I}_{1}$ and $\dot{I}_{2}$ are the same feeding in to the bus internal fault, whereas the current directions of $\dot{I}_{1}$ and $\dot{I}_{2}$ are opposite when it is a bus external fault as shown in Fig. 6 (b).

Reference [32] uses the ratio of the bus voltage to the sum of the branch currents to detect internal faults and external faults, and this ratio uses the integrated information and is defined as the integrated impedance. Some papers have proposed power differential protective principles, which analyze the integrated comprehensive information to reflect the power unbalances caused by system faults.

\section{Some issues can be solved by integrated information}

The term IP is used to denote the integration of protective devices for multiple power apparatuses within a substation into one protective relay. Regional and comprehensive information is the most significant advantage of IP. Thus, additional functions and criterions can be proposed through analyzing the redundant information. A novel scheme based on the sine degree is proposed for distinguishing the transformer magnetizing inrush current and the power system fault currents [33]. Similarly, more effective CT saturation criterions and VT breaking criterions are proposed based on integrated information analysis.

\section{Other substation automation functions}

Maintaining the operation of a continuous process is generally the highest priority when part of the energy supply system is lost. Noncritical loads may be shedded when the utility supply fails. In that case, the process must be powered by whatever available on-site generation. Taking advantages of integrated regional information, an optimal comprehensive cost model for under frequency load shedding (UFLS) is proposed in [34], and other optimal load shedding strategies are presented in $[35,36]$.

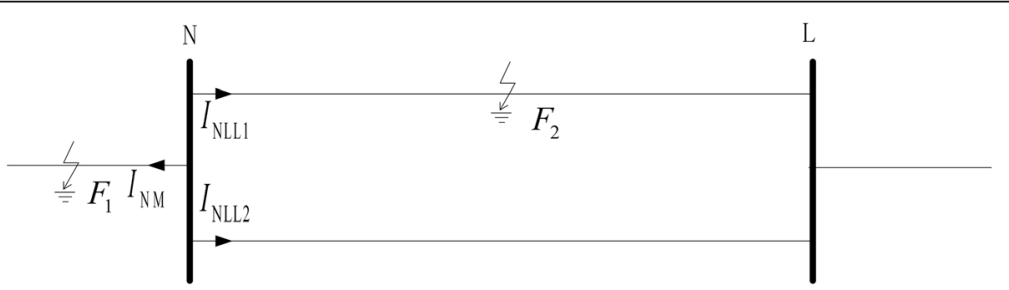

Fig. 5 Internal and external faults of parallel lines. F1 is an external fault of the parallel lines and F2 is an internal fault. Three currents ( / $I_{\mathrm{NM}} /_{\mathrm{NLL}}$ and $\left.I_{\mathrm{NLL2}}\right)$ are analyzed to demonstrate the polarity protection principle 


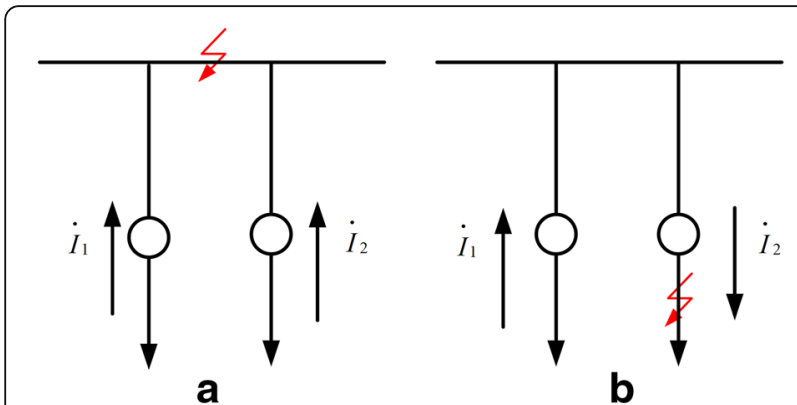

Fig. $\mathbf{6}$ Bus fault situations. $\mathbf{a}$ is the internal fault of bus. $\mathbf{b}$ is the external fault of bus

\section{A new coordinated protection system}

Most researches described above focus on the analysis of data, which depends on integrated information acquisition. Protection considering coordination of different units and functions needs further study. A novel solution utilizes the information acquisition mode of a digital substation and the communication network of a smart grid is proposed in this section.

Referred as a coordinated substation protection (CSP), it implements the corresponding protection configuration principles and concentrates on the coordination and cooperation among different intelligent electronic devices (IEDs) within a substation. It utilizes the communication network and the data acquisition capability available within a digital substation. Compared with the existing integrated protection approach, IEDs with distributed processing have more advantages in terms of functional support and information utilization. The local information coordination of IEDs improves the reliability of the fault identification process, and the CSP has stronger independence and higher reliability compared with the traditional backup protection scheme. The detailed functional realization, communication network and the operating principles are discussed below.

\section{Functional realization}

CSP is a new application concept which utilizes the standardized communication protocol and the secure information network available in a digital substation. The Process Level accomplishes synchronous sample value acquisition, action command execution and breaker status uploading. The Bay Level consists of a number of IEDs which work in a harmonious and coordinated manner to provide reliable fault detection. The coordination of IEDs includes information sharing and coordinated backup tripping. The Station Level integrates useful data and events for substation management and provides communication with the control center or a SDH network.

Figure 7 shows the structure of a substation based on coordination and cooperation between different protection IEDs. In terms of functionality, an IED integrates the function module (FM), local coordination module (LCM) and remote coordination module (RCM). FM is responsible for the protection algorithm, which processes the samples received from the process bus, performs the protection calculations and sends the action commands to the breaker. At the same time, FM can communicate with other IEDs to share information and deliver coordinated tripping of the breakers in a coordinated manner. LCM is the module which monitors the requirements of the local IED. It establishes the appropriate tasks and sends the commands. RCM receives remote commands from other IEDs and analyses their requirements, or receives remote information and use

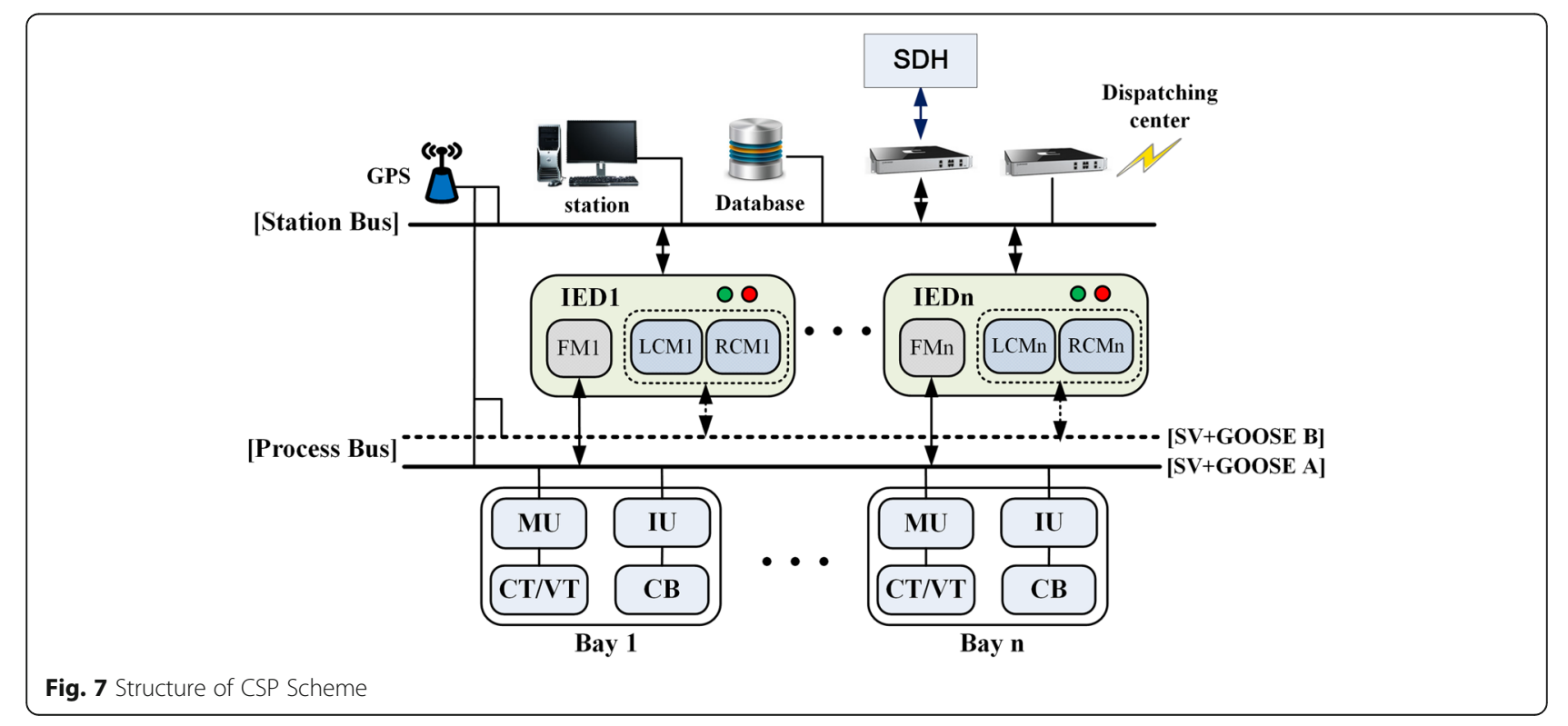


this for local processing. The protection uses an ownerless structure and provides redundancy in the case of IED failures. The IED is based on a modulus design principle and is easy to recombine or extend functionality via the standard module interface.

CSP is substation-domain protection system, and its protection range is elements within the substation and the outgoing-lines. Coordinated IEDs implement local high speed protection decisions, whilst other IEDs exchange information with adjacent substations to allow the protection of outgoing-lines. If a primary equipment (CT, VT or $\mathrm{CB}$ ) is in an abnormal working state, the IEDs work in a coordinated mode, using data sharing and coordinated tripping to improve the reliability of the local substation protection.

\section{Communication network}

A reliable communication network is one of the key elements in a CSP scheme. The communications network includes two parts: the substation based process level communication network and communications between adjacent substations.

The process level communication network is shown in Fig. 7. Based on the IEC61850-9-2LE standard, the communications between the bay level and the process level are via the process bus and a high performance local area network (LAN) [5] which carries sampled values (SV) and GOOSE messages. Considering the large quantities of information and the network load capacity, a dual process network is established within a substation. The FM performs protection calculations and communicates with the primary equipment through the LAN "SV + GOOSE A". The LCM and RCM are responsible for coordination, and communicate with their corresponding modules in the other IEDs through LAN "SV + GOOSE B". To synchronize the different data sources, LAN communication should have an accurate and reliable GPS synchronous timemarker.

One substation can exchange the information of outgoing-lines with the adjacent substations, to implement cooperation between the different substations. Network communications with adjacent substations are based on SDH technology and operate in a self-healing ring mode. The substations connect with all the other IEDs in the ring, allowing flexible data acquisition to be achieved. As shown in Fig. 8, substations S_2 and S_3 upload data to the SDH network using an SDH device, and substation S_1 can download the necessary data from the SDH network for protection decisions in its substation domain.

CSP for the substations implements rapid fault judgment and the coordination working mode, and consequently it improves protection reliability. The local protection function which analyzes the local information, works as the main protection and the coordination working mode is based on coordinated sharing information to detect the fault when the main protection fails to clear the fault. Independent operation and tripping without time delays helps to promote the application.

\section{Methods}

Current differential protection is not affected by bidirectional power flow, and can identify faults correctly and rapidly, without the need for VTs to provide directionality. The differential principle can be easily applied within a substation and involves the cooperation of multiple IEDs by sharing information and using functional coordination to implement an adaptive differential protection scheme. The basic principle is to use the nearest correct data when the local data is erroneous. In addition, if the local protection or its breaker has not operated correctly, the protection trip boundary will be broadened to ensure the protection can clear the fault.

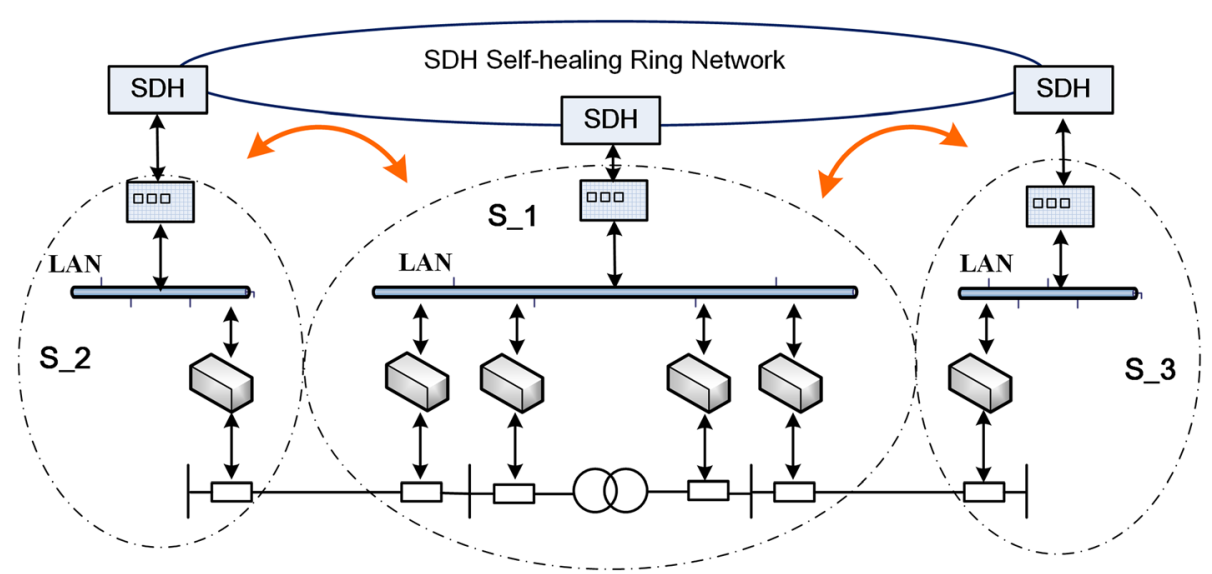

Fig. 8 Communication network of CSP. The S_1, S_2 and S_3 are three adjacent substations 
Using the CSP concept, an IEC61850 based system for a typical $110 \mathrm{kV}-35 \mathrm{kV}-10 \mathrm{kV}$ substation is designed as shown in Fig. 9. On the basis of local protection area of single instrument and approaches of information sharing, multi-level extended protection regions are established. M1 to M19 denote measurement devices at different locations. Several different protection regions are described in terms of protection scale, data included and function level in Table 2.

The protection system implements substation domain protection based on the differential principle. As an example, the fault location in the system as shown in Fig. 9 is considered to analyze the coordination working mode. The current positive direction is assumed to be from a bus to a line. Current pairs $\left(\dot{I}_{14}, \dot{I}_{16}, \dot{I}_{17}\right),\left(\dot{I}_{3}, \dot{I}_{4}\right.$, $\left.\dot{I}_{16}\right)$ and $\left(\dot{I}_{4}, \dot{I}_{19}\right)$ are the currents at the terminals of transformer 1, $35 \mathrm{kV}$ bus 1 and line 4-19, respectively. The differential current dif $f_{1}$ of transformer 1 is $\left|\dot{I}_{14}+\dot{I}_{16}+\dot{I}_{17}\right|$. If the local data $\dot{I}_{16}$ is not available, it can be replaced by $-\dot{I}_{4}$ and $-\dot{I}_{3}$ through information coordination with IED (35 kV bus 1). The information sharing is achieved through the process bus LAN "SV + GOOSE B" and the new differential current $\operatorname{dif}_{2}$ is $\left|\dot{I}_{14}+\dot{I}_{17}-\left(\dot{I}_{4}+\dot{I}_{3}\right)\right|$. The minus operator is used because
$\left(\dot{I}_{4}+\dot{I}_{3}\right)$ are defined with an opposite direction to $\dot{I}_{16}$. Similarly, if $\dot{I}_{4}$ is not available, it can be replaced by $-\dot{I}_{19}$ through coordination with IED (line) and the differential current $\operatorname{dif}_{3}$ is $\left.\mid \dot{I}_{14}+\dot{I}_{17}-\dot{I}_{3}+\dot{I}_{19}\right) \mid$.

\section{Results}

A single phase-to-ground fault was applied at the fault location $\mathrm{F}$ and the three differential currents $\left(\operatorname{dif}_{1}\right.$, dif $_{2}$, dif $_{3}$ ) were calculated as discussed above and are shown in Fig. 10. As seen, the differential currents increase significantly immediate after fault occurrence and the trajectory intersects the operation threshold at $0.503 \mathrm{~s}$. It is obvious that, differential protection using information sharing can judge the fault effectively. The partial enlarged figure shows the differential currents $\mathrm{dif}_{2}$ and $\mathrm{dif}_{3}$ are higher than $d i f_{1}$. The reason is that information coordination brings greater measurement errors and distributed capacitance current, both of which contribute to the differential current. In a real application, this error can be large when one considers the communication error of the IEDs and the data conversion error. Therefore, the protection setting should take this error into consideration.

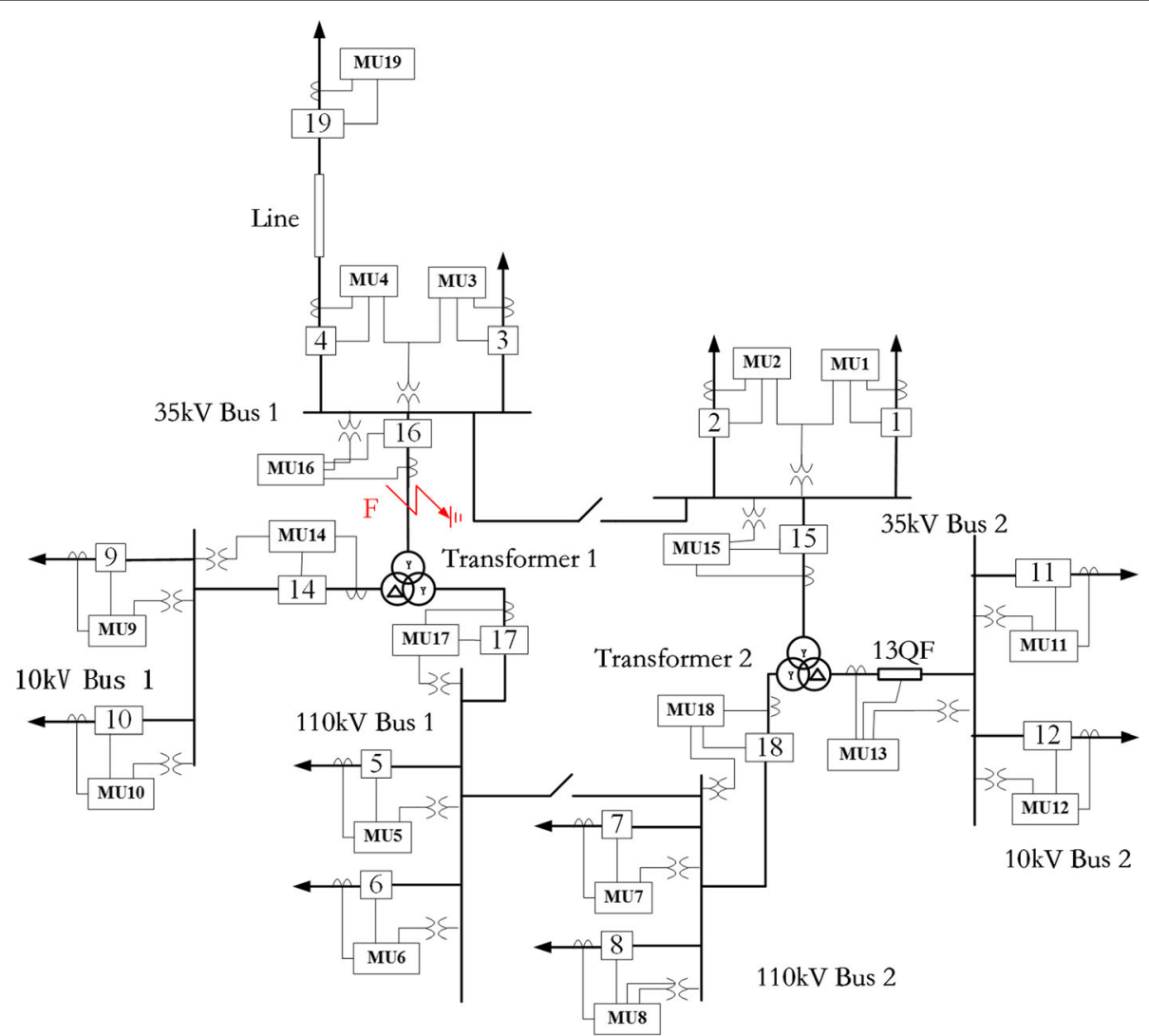

Fig. 9 A typical 110 kV-35 kV-10 kV substation system diagram. F means a fault location 
Table 2 Division of functional regions

\begin{tabular}{llll}
\hline $\begin{array}{l}\text { Functional } \\
\text { region }\end{array}$ & Protection Scale & Data & Function Level \\
\hline 1 & Transformer 1 & M14, M16, M17 & । \\
2 & 35 kV Bus 1 & M3, M4, M16 & । \\
3 & Transformer 1 & M3, M4, M14, M17 & II \\
& \& 35 kV Bus 1 & \\
4 & Transformer T & M3, M14, M17, M19 & III \\
& \& 35 kV Bus 1 & \\
& \& Line 4-19 & & \\
\hline
\end{tabular}

Figure 11 depicts the variations of instantaneous current, RMS voltage, active power and reactive power of the MU 17. The circuit breakers are tripped at $0.59 \mathrm{~s}$ and it can be seen in Fig. 11 that the current becomes zero at the instant fault section clearance whereas the voltage, active/reactive powers become zero a short time after the fault isolation. The total fault clearing time takes into consideration of the time delay components which are sensor delay (5 ms), communication delay ( $5 \mu$ s which is negligible), integrated protection unit delay (dependent on the protection principle) and circuit breaker delay $(90 \mathrm{~ms})$. The time of IED coordination is not considered in this paper. However, the time cost is related to the communication delay and coordination strategy. Actually, the data networks of smart substations have short communication time cost, thus the application of simplified information coordination should be given more attention.

On the other hand, when the circuit breaker fails to clear the fault, adjacent circuit breakers could work in a coordinated mode to reduce the outage area. For example, when a fault occurs at the line 4-19 and circuit breakers 4 \& 19 fail to clear the fault section, protection IED of the $35 \mathrm{kV}$ Bus 1 would send tripping commands to circuit breaker 16 to clear the fault instead.

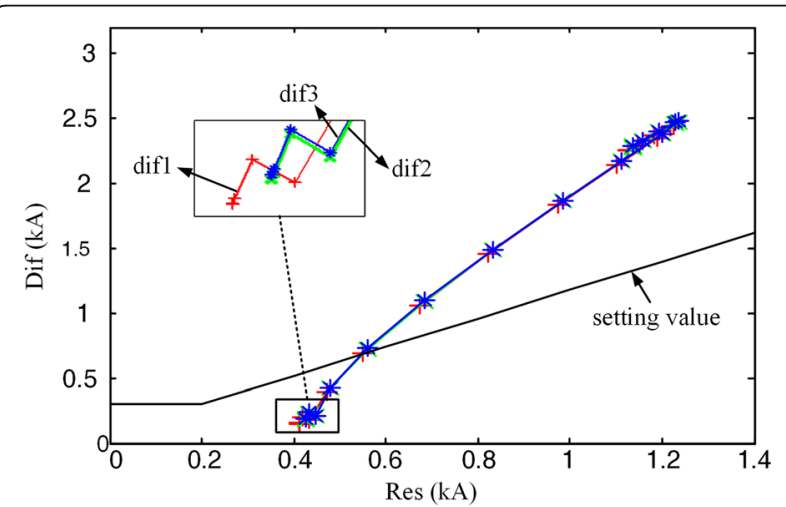

Fig. 10 Differential currents with fault F. Dif means the differential current and Res is the restraint current

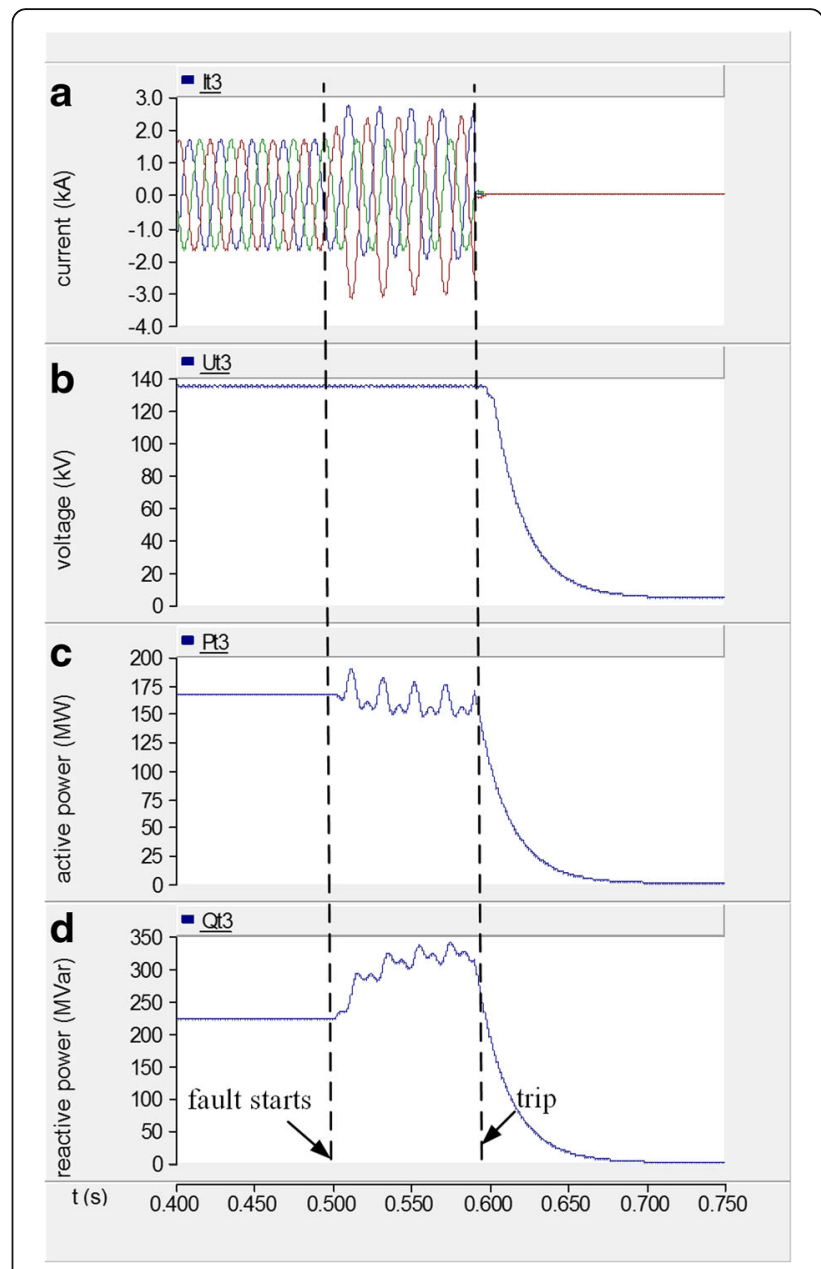

Fig. 11 Simulation results. $\mathbf{a}$ is the instantaneous current, $\mathbf{b}$ is the voltage RMS, $\mathbf{c}$ is the active powers and $\mathbf{d}$ is the reactive powers of the MU 17 following a single phase to ground fault at location $F$

\section{Discussion}

The application costs of the proposed CSP system are related to the costs of the communications infrastructure, hardware architecture and software applications. Actually, using third-party public-switched data networks in active distribution network is suitable from the economic standpoint and the communication time cost may be short. Applying the differential princple to the proposed protection system, there is no additional cost for VTs. However, the cost of protection IEDs should be given more attention.

\section{Conclusion}

In recent years, the progresses in microprocessor, communication and transducer technologies have provided new means for the design and development of new generation of power system protection scheme. The term "Integrated Protection" is used to denote the integration of several protective devices for multiple power equipment within 
the substation into one protective relay, obtaining all the real time information of the substation by communication network. The business driver behind functional integration is cost reduction by reduced hardware, wiring and installation times. It is also expected that it will lead to a reduction in life-time operational costs.

In this paper, several different kinds of integrated protection schemes and their respective advantages and disadvantages are discussed. Protection principles and functions applied in integrated protection systems are also presented. A new coordinated protection system based on inter-substation information is proposed and simulation results illustrate and verify the feasibility of the scheme.

\section{Acknowledgment}

This work is supported by the National Natural Science Foundation of China under Grant 51277009, and the Application Technology Research and Engineering Demonstration Program of National Energy Administration under Grant NY20150302.

\section{Authors' contributions}

$\mathrm{JH}$ contributed to the study design and analysis and drafted the manuscript; LL was involved in data acquisition, analysis and revision of the manuscript; WL worked on aspects of the study relating to inter-substation information protection system; MZ was involved in data acquisition and revision of the manuscript. All authors have read and approved the final manuscript.

\section{Competing interests}

The authors declare that they have no competing interests.

Received: 2 June 2016 Accepted: 22 October 2016

Published online: 28 October 2016

\section{References}

1. Blackburn, JL. (1987). Protective relaying principles and applications. New York, Marcel Dekker

2. Ackeman, T, Anderson, M, \& Seder, L. (2001). Distributed Generation: a Definition. Electric Power System Research, 57, 195-204.

3. Jiang, ZH, Li, FX, Qiao, W, Sun, HB, Wang, JH, Xia, Y, Xu, Z, Zhang, P. (2009). A Vision of Smart Transmission Grids. In PES 'O9 IEEE Power \& Energy Society General Meeting Calgary, AB, Canada. (pp. 6-10). Piscataway: IEEE.

4. Chen, L, Zhang, KJ, Xia, YJ, Hu, G. (2012). Study on the substation area backup protection in smart substation. In IEEE PES Asia-Pacific Power and Energy Engineering Conference (APPEEC) Shanghai, China. (pp. 1-4). Piscataway: IEEE.

5. Li, ZX, Yin, XG, Zhang, Z, \& He, ZQ. (2013). Wide-area protection fault identification algorithm based on multi-information fusion. IEEE Transactions on Power Delivery, 28, 1348-1355.

6. Serizawa, Y, Tanaka, T, Fujikawa, F, Sugiura, H, Shioyama, T, Kimura, Y. (2012). Use case study on a decentralized modular device network for wide-area monitoring, protection and control. In 2012 IEEE Power And Energy Society General Meeting, San Diego, CA, USA. (pp. 1-8). Piscataway: IEEE.

7. Su, S, Li, KK, \& Chan, WL. (2010). Adaptive agent-based wide-area current differential protection system. IEEE Transactions on Industry Applications, 46, 2111-2117.

8. Abdulhadi, I, Coffele, F, Dysko, A, Booth, C, Burt, G. (2011). Adaptive protection architecture for the smart grid. In 2011 2nd Innovative Smart Grid Technologies (ISGT Europe) Anaheim, Manchester, UK. (pp. 1-8). Piscataway: IEEE.

9. Adamiak, MG, Apostolov, AP, Begovic, MM, Henville, CF, Martin, KE, Mechel, GL, Phadke, AG, \& Thorp, JS. (2006). Wide Area Protection-Technology and Infrastructures. IEEE Transactions on Power Delivery, 21, 601-609.

10. Ingelsson, B, Sweden, SK, Lindstrom, PO, Karlsson, D, \& Runvik, G. (1997). Wide-area protection against voltage collapse. Computer Applications in Power IEEE, 10, 30-35.

11. Li, J, He, JH, Zhang, H, \& Xie, FX. (2011). Research on adaptive protection based on integrated protection. Advanced Power System Automation and Protection (APAP), 2, 848-852.
12. Zhang, H, He, JH. (2008). Design of a real-time substation communication system for integrated protection. In Transmission and Distribution Conference and Exposition: Latin America, Bogota, Colombia. (pp. 1-5). Piscataway: IEEE.

13. Gungor, VC, Sahin, D, Kocak, T, Ergut, S, Buccella, C, Cecati, C, \& Hancke, GP. (2011). Smart Grid Technologies: Communication Technologies and Standards. IEEE Transactions on Industrial Informatics, 7, 293-297.

14. Lin, XN, Li, ZT, \& Wu, KC. (2009). Principles and implementations of hierarchical region defensive systems of power grid. IEEE Transactions on Power Delivery, 24, 30-37.

15. Giovanini, R, Hopkinson, K, Coury, DV, \& Thorp, J. (2006). A primary and backup cooperative protection system based on wide area agents. IEEE Transactions on Power Delivery, 21, 1222-1230.

16. Serizawa, Y, Imamura, H, \& Kiuchi, M. (2001). Performance evaluation of IP-based relay communications for wide-area protection employing external time synchronization. Proceedings of the IEEE Power Eng. Soc. Summer Meet, 2, 909-914.

17. Bo, ZQ, He, JH, Dong, XZ, Caunce, B.R.J (2006). Overcurrent Relay based Integrated Protection Scheme for Distribution Systems. A. In International Conference on Universities Power System Technology, Chongqing, China. (pp. 1-6). Piscataway: IEEE.

18. $\mathrm{Xu}, \mathrm{ZY}, \mathrm{Du}, \mathrm{ZQ}$, Ran, L, et al. (2007). A current differential relay for a $1000 \mathrm{kV}$ UHV transmission line. IEEE Transactions on Power Delivery, 22, 1392-1399.

19. Serizawa, Y, Myoujin, M, Kitamura, K, Sugaya, N, Hori, M, Takeuchi, A, et al. (1998). Wide-area current differential backup protection employing broadband communications and time transfer systems. IEEE Transactions on Power Delivery, 13, 1046-1052.

20. Kangvansaichol, K, \& Crossley, PA. (2003). Multi-zone current differential protection for transmission networks. Proc. IEEE Power Engineering Soc. Transmission Distribution Conf. Expo, 1, 359-364.

21. Wang, HG, Du, DX, Bo, ZQ, Dong, X. (2006). An Integrated Current Differential Protection Scheme. In 2006 International Conference on Power System Technology, Chongging, China. (pp 1-6). Piscataway: IEEE.

22. Song, S, \& Zou, G. (2015). A Novel Busbar Protection Method Based on Polarity Comparison of Superimposed Current. IEEE Transactions on Power Delivery, 30(4), 1914-1922.

23. Zadeh, MRD, Sidhu, TS, \& Klimek, A. (2011). Implementation and testing of directional comparison bus protection based on IEC61850 process bus. IEEE Transactions on Power Delivery, 26(3), 1530-1537.

24. Bo, ZQ, He, JH, Dong, XZ, Caunce, BRJ. (2006). An integrated protection scheme based on a distance approach. In the 41st International Universities Power Engineering Conference, Newcastle upon Tyne, UK. (pp. 800-803) Piscataway: IEEE.

25. Suonan, J, Deng, X, \& Liu, K. (2011). Transmission line pilot protection principle based on integrated impedance. IET Generation Transmission and Distribution, 5, 1003-1010.

26. Stedall, B, Moore, P, Johns, A, Goody, J, \& Burt, M. (1996). An investigation into the use of adaptive setting techniques for improved distance back-up protection. IEEE Transactions on Power Delivery, 11(2), 757-762.

27. Rockefeller, GD, Wagner, CL, Linders, JR, Hicks, KL, \& Rizy, DT. (1988). Adaptive Transmission Relaying Concepts for Improved Performance. IEEE Transactions on Power Delivery, 3(4), 1446-1456.

28. Bo, Z.Q, Han, M, Klimek, A, Zhang, BH, He, JH, Dong, XZ. (2009). A Centralized Protection Scheme Based on Combined Positional Protection Techniques. In 2009 IEEE Power \& Energy Society General Meeting, Calgary, AB, Canada. (pp. 1-6). Piscataway: IEEE.

29. Jinghan He, Biao Zhang, Z. Q. Bo. (2007). Parallel line integrated protection based on transient current polarity comparison. In 2007 Klimek Universities Power Engineering Conference, Brighton, UK. (pp. 597-601). Piscataway: IEEE.

30. Gao, H, Liu, Y, Zou, G, Cui, D, Liu, M, Li, X. (2014). Principle and Implementation of Substation-Area Backup Protection for Digital Substation. In the 12th IET International Conference on Developments in Power System Protection, Copenhagen, Denmark. (pp. 1-5) Piscataway: IEEE.

31. Wu, CY, He, JH, Zhang, H, \& Zhi, ZQ. (2012). Design of bus protection for integrated protection. Power System Protection and Control, 40, 125-130.

32. Suonan, J-I, Deng, X-y, Alimu, J, et al. (2010). A novel principle of integrated impedance based bus-bar protection. Power System Protection and Control, 38, 1-7.

33. Han, JH, Li, JZ, Yao, B, \& Ou, ZJ. (2007). New Approach of Transformer Inrush Detected Based on the Sine Degree Principle of Current Waveforms. Proceedings of the CSEE, 27, 54-58. 
34. Han, JH, Bo, DD, Wang, XJ, \& Ye, HD. (2013). An Optimal Algorithm of Comprehensive Cost for Under Frequency Load Shedding. Power System Technology, 37, 3461-3465.

35. Bo, DD, Han, JH, Wang, XJ, \& Ye, HD. (2014). Adaptive UFLS scheme based on grey correlation analysis. Power System Protection and Control, 42, 20-25.

36. Han, JH, Chen, ZL, Ye, HD, Liu, L, \& Xu, YK. (2015). Optimization Scheme for Under-Voltage Load Shedding Wide-Area Configuration and SubstationArea Setting. Power System Technology, 39, 2333-2339.

\section{Submit your manuscript to a SpringerOpen ${ }^{\circ}$ journal and benefit from:}

- Convenient online submission

- Rigorous peer review

- Immediate publication on acceptance

- Open access: articles freely available online

- High visibility within the field

- Retaining the copyright to your article

Submit your next manuscript at $>$ springeropen.com 